\title{
HF RADAR INSTRUMENTS, PAST TO PRESENT
}

\author{
By Calvin C. Teague, John. F. Vesecky \\ and Daniel M. Fernandez
}

\section{That observation \\ launched the field \\ that is now termed \\ "radar oceanogra- \\ phy," the use of \\ radar systems to}

study oceanographic

properties.

\section{$\mathrm{R}$} ADAR RETURNS FROM the ocean surface have been observed since the earliest days of radar. They were characterized as "clutter" because they often obscured targets, such as ships or aircraft. However, Crombie (1955) observed that some high-frequency ( $\mathrm{HF}, 3-30 \mathrm{MHz}$ ) signals recorded near the sea had a distinctive Doppler shift of a fraction of a hertz above and below the transmitted signal. He correctly deduced that they were the result of Bragg scattering by ocean waves that were traveling radially toward or away from the radar and had a wavelength of one-half the radar wavelength. That observation launched the field that is now termed "radar oceanography," the use of radar systems to study oceanographic properties. Radar systems can be characterized by a number of parameters including operating frequency, geometry, platform, propagation mode, means of obtaining distance and angular resolution, etc. In the limited space of this paper only a few of the highlights of HF systems can be covered. For indepth reviews, the reader is referred to articles by Croft (1972), Barrick (1978), and Shearman (1981, 1983).

\section{Radar Operation}

An oceanographic radar differs somewhat from a radar intended to track ships or aircraft. First is the operating frequency; most aircraft radars operate at microwave frequencies with wavelengths on the order of centimeters, whereas the radars that are the subject of this issue operate in the HF range with wavelengths of tens of meters. This is important because the energetic ocean waves interact directly with an HF radar signal rather than in-

Calvin C. Teague. Space, Telecommunications and Radioscience Laboratory, Stanford University, Stanford, CA 94305-9515, USA; John F. Vesecky, Department of Atmospheric, Oceanic, and Space Science, 2455 Hayward, University of Michigan, Ann Arbor, MI 48109-2143. USA; Daniel M. Fernandez, Institute of Earth Systems Science and Policy, California State University, Monterey Bay, 100 Campus Center. Seaside, CA 93955-8001. USA. directly as they do in microwave systems. Second, because the wavelengths are so large the directivity that can be obtained by physical antennas is limited. Here we define directivity as a measure of the antenna array's capability to resolve a given direction. Third, direction scanning usually is confined to just azimuth, rather than azimuth and elevation. The main measurements performed by typical HF radars are the range or distance to the target, the direction to the target as a bearing from some reference azimuth, the Doppler frequency of the target, and the power of the signal returned by the target. Here, the target is a patch of ocean.

\section{Distance Measurement}

Single pulse. The simplest means of determining distance is to use a short pulse of radar energy. The range resolution is given by $\mathrm{ct} / 2$ where $\mathrm{c}$ is the velocity of light, $3 \times 10^{8} \mathrm{~m} \mathrm{~s}^{-1}$, and $t$ is the pulse width in seconds. A disadvantage of this technique is that if the pulse is short to obtain good range resolution, the average power transmitted power is low and so is the resulting signal-tonoise ratio of the received signal, thus limiting the radar range.

Coded waveform. An alternative to a single pulse is a coded waveform. Figure 1 illustrates an 11-element Barker code used to observe two targets of unequal amplitudes. The radar transmits a sequence of short pulses coded so their autocorrelation function has a single, sharp central peak and low sidelobes. The range resolution is determined by the width of the individual pulses but the average power is raised by the number of pulses in the sequence. There are some limitations to this approach, however. If the sequence is too long, short-range targets cannot be seen because a portion of the echo arrives while the later part of the sequence is still being transmitted. (Most radars cannot receive signals while they are transmitting, because of severe overloading of the receiver.) Figure 1 also illustrates another problem of coded waveforms; there can be spurious responses (range sidelobes) from strong targets. Both of these prob- 
lems can be reduced or eliminated by using more complicated waveforms, at the expense of additional data processing.

$F M C W$. Instead of transmitting short pulses, a radar can transmit a relatively long frequencymodulated (FM) continuous-wave (CW) signal as sketched in Figure 2. If the transmitted frequency is linearly swept and used as a reference for the received signals, a target at a particular range will produce a constant difference frequency whose value depends on its distance; more distant targets will produce higher frequencies. By analyzing the frequency content of the returned signal, targets at various ranges can be discerned. For most radars, the linear sweep is interrupted periodically to avoid overloading the receiver during reception of the echo.

\section{Doppler Measurement}

Doppler resolution, used to measure the velocity of the target, is obtained by repeating the range measurements, whether single pulse, coded waveform, or FMCW, at a regular rate and performing a time-series analysis on the samples obtained from each individual range measurement. A coherent integration time of $\mathrm{T} s$ provides a frequency resolution of roughly $\Delta f=1 / T \mathrm{~Hz}$. The target velocity resolution, in turn, is given by $\Delta v=\lambda \Delta f / 2$ $\mathrm{m} \mathrm{s}^{-1}$, where $\lambda$ is the radar wavelength in meters.

\section{Azimuth Angle Measurement}

Because of the long wavelengths involved, HF radars do not physically move antennas to look in different directions. Rather, they control the direction to which they are sensitive electronically using a variety of techniques.

Phased array. Conceptually, the simplest antenna system is a phased array of identical receiving elements spaced no more than $\lambda / 2$ apart (to avoid severe sidelobes) with the line of the array perpendicular to the center of the desired set of beam directions. The beam is steered by adjusting the amplitude and phase of the signals from each of the elements and adding these signals coherently. The phase adjustment can be done using physical devices (coaxial cables, phase-shift networks, etc.) or digitally in the data processing after the signals from each element have been separately recorded. The angular resolution that can be obtained from an array with a total aperture of D is roughly $\lambda / \mathrm{D}$ radians. To obtain an angular resolution of $5^{\circ}(0.1$ radian $)$, an aperture of $10 \lambda$ is required. In practice, it may not be possible to obtain enough area on a beach for this resolution, particularly at frequencies below $10 \mathrm{MHz}$.

Synthetic aperture. At the low end of the HF spectrum, it is impractical to obtain any appreciable directivity with a physical aperture. However, it is possible to use a technique borrowed from satellite technology, synthetic aperture. A simple antenna, for example, a loop or short whip, is carried along a straight line at a constant velocity that

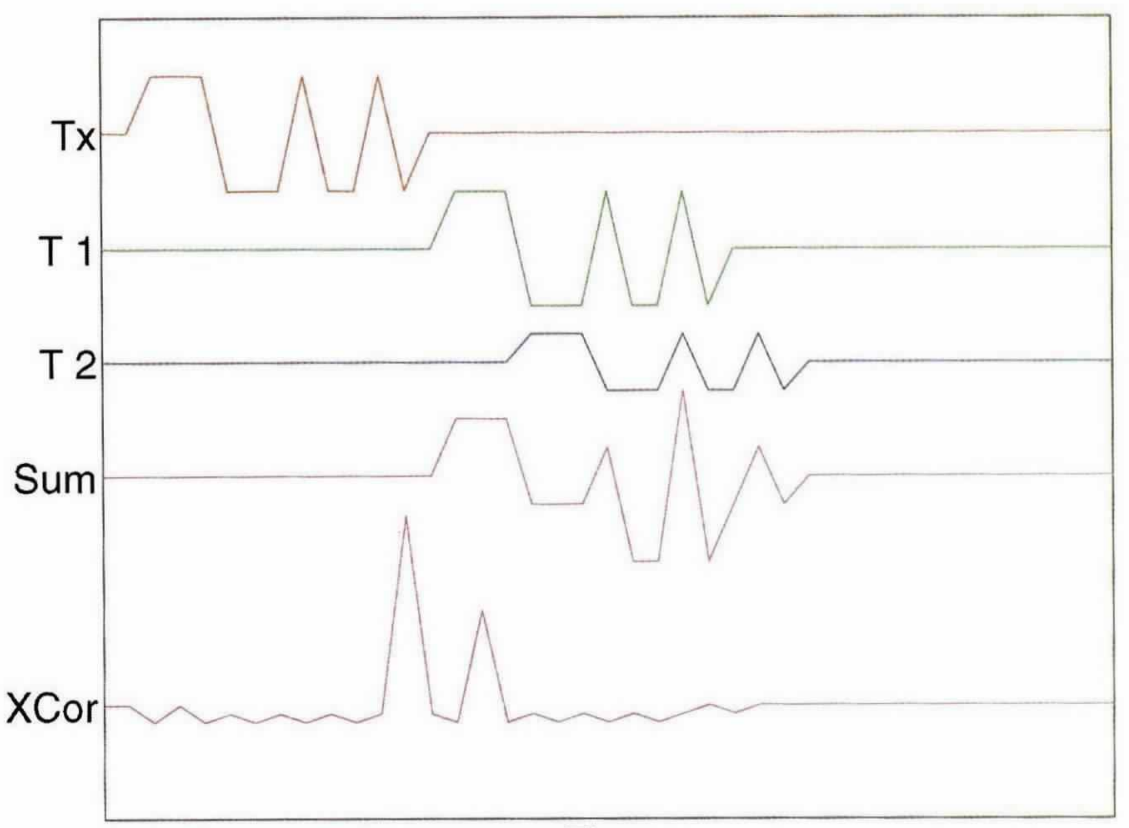

Time

Fig. 1: Sketch of waveforms for a radar using an 11-element Barker code. The transmitted waveform (Tx) is at the top, followed by individual returns from two discrete targets $(T 1, T 2)$ of relative amplitude 1.0 and 0.5 , their sum (Sum), and the cross-correlation function (XCor) between the received composite signal and the transmitted signal at the bottom. The two targets are clearly resolved.

is less than the phase velocity of the Bragg-resonant ocean waves. The motion of the antenna spreads a narrow Bragg line into a band of direction-dependent frequencies, and Fourier analysis of the signals can yield their direction of arrival if it is assumed that currents are insignificant compared with the phase velocity of the Bragg waves. This technique works best at low frequencies (2 $\mathrm{MHz}, \lambda=150 \mathrm{~m}$ ) and apertures of up to $2 \mathrm{~km}$ have been synthesized this way (Tyler et al. 1974; Shearman 1981).

Direction finding. An alternative to the beamforming techniques is direction finding. The signals from two or more relatively closely spaced (Crombie 1972) or even co-located (Barrick et al., 1977) antennas are compared, either in phase or amplitude. This is done at each frequency bin in the analysis bandwidth. With $\mathrm{N}$ antennas, it is possible to resolve at most $\mathrm{N}-1$ directions at each frequency. A significant advantage of this technique is that the antennas are much smaller than in a phased array.

With all of these techniques, it is important that the amplitude and phase response of the antennas is very well known. Usually it is not sufficient to depend on ideal theoretical patterns or even electromagnetic modeling programs. Antenna-ground planes, cables, buried conductors, fences, and finite ground conductivity all contribute to the antenna patterns and ultimately they must be measured, usually with a portable signal source or a transponder. As the desired directivity
. . . the simplest

antenna system is a phased array of identical receiving elements . . .

An alternative to the beamforming techniques is direction finding. 


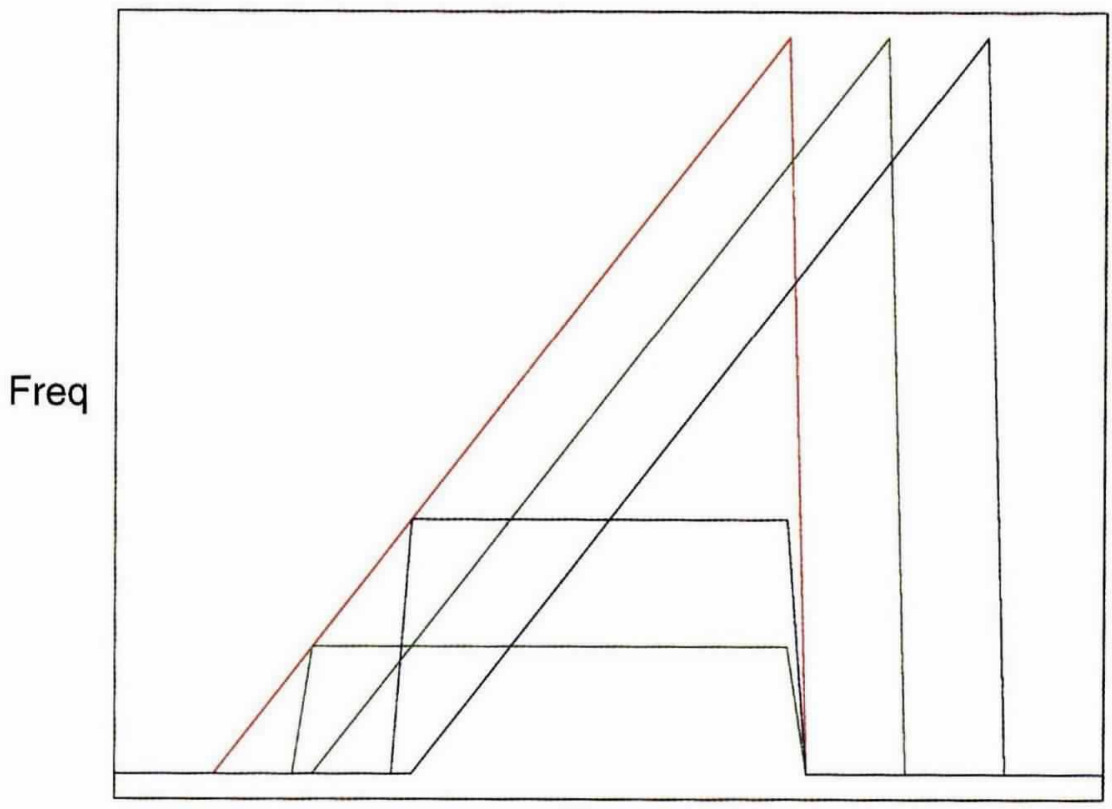

Time

Fig. 2: Sketch of transmitted and received signals for an FMCW system. The transmitted waveform is shown in red, with returns from two different targets shown in green and blue. The frequency difference (---) between the transmitted and received signals is constant with time and has a larger value for more distant targets.

\section{Another significant}

result from this ex-

periment was a mea-

sure of the absolute

value of the radar

cross section of the

ocean . . . increases, so does the required precision of the required antenna pattern measurement.

\section{Wave Measurements}

Early wave measurements were made using both monostatic (co-located transmitter and receiver) and bistatic (separated transmitter and receiver) geometries, radars located on land and on ships, various antenna configurations, and surface wave and sky wave (ionospheric) radio propagation. Estimation of ocean wave parameters using surface-wave radars usually involves receiving first-order scattered signals from a wide range of angles and assumes that the sea is homogeneous over the area surveyed; sky-wave radars generally look in a narrow range of directions and make use of the second-order signals. A few key experiments are mentioned below.

\section{Bistatic Geometry}

In the late 1960s Allen Peterson of Stanford University collaborated with Walter Munk and Bill Nierenberg of the Scripps Institution of Oceanography to investigate techniques of using HF surface-wave radar to make oceanographic measurements over large areas. Under Office of Naval Research sponsorship, Peterson, C.C. Teague, and G.L. Tyler of the Radioscience Laboratory at Stanford began experiments along the northern California coast using Prof. Peterson's weekend cottage at Sunset Beach (south of Santa Cruz) as a field site. These experiments led to the first HF radar measurements of directional wave spectra for ocean swell (Peterson et al., 1970). They employed a bistatic geometry, which made use of LORAN-A transmitters operating near $1.9 \mathrm{MHz}$. These transmitters, now removed from service, had a peak power of many hundreds of kilowatts and used short pulses, so they made an ideal transmitter for a radar system. By receiving the direct signal and echoes a few hundred kilometers from the transmitter, it was possible to map a portion of the ocean-wave directional spectrum to the received Doppler shift by assuming that the sea was homogeneous over the observation region and that currents were small (Teague, 1971). However, because of gaps in coverage of the ocean wave spectrum, other techniques were sought.

\section{Synthetic Aperture}

Steady state. Several experiments were performed using a synthetic aperture receiving antenna in conjunction with LORAN-A transmitters. For these experiments, a small antenna was carried on a vehicle traveling in a straight line at a constant velocity close to the transmitter so that the geometry was essentially monostatic. In an experiment at Wake Island, a small island in the trade winds region, the directional distribution of $77 \mathrm{~m}$ ocean waves was measured under fully developed conditions (Tyler et al., 1974). The directional distribution was found to be consistent with a $\cos ^{s}(\theta / 2)$ form, with $s$ in the range of $2-12$, and with a small pedestal to account for $\sim 1 \%$ of the wave energy traveling upwind. Another significant result from this experiment was a measure of the absolute value of the radar cross section of the ocean (Teague et al., 1975). This measurement was made by observing the ratio of the echo energy to the direct energy from the transmitter a few kilometers from the receiver. Similar experiments were performed in the United Kingdom by Shearman et al. (1979) using a former LORAN-A transmitter in Wales.

Wave growth and shadowing. An experiment complementary to Wake Island was performed at Galveston, TX, along a long straight coastline (Stewart and Teague, 1980). Observations were made after the wind had shifted from onshore to offshore and the wave growth with distance and time was measured, again using a nearby LORAN-A transmitter. In Southern California wave shadowing by San Clemente and San Nicholas Islands was reported by Vesecky et al. (1980).

\section{Phased Array}

A dual-frequency phased-array radar was operated on the French Mediterranean coast by the University of Toulon (Broche, 1979) and used to estimate the significant wave height $\mathrm{H}_{1 / 3}$, dominant wave frequency, and wind direction. A similar radar was used by the Institut Français du Petrole in the Shetland Islands (Shearman, 1983). A multifrequency radar constructed at Stanford Univer- 
sity was operated on a ship during the 1978 Joint Air-Sea Interaction (JASIN) experiment (Teague. 1986). Although the emphasis in this issue is on surface-wave propagation, several sky-wave phased-array radars employing very narrow beam widths have been used. Maresca and Georges (1980) describe the $2.5 \mathrm{~km}$ Wide Aperture Research Facility (WARF) operated by SRI International, and Georges and Harlan (1994) describe the use of military surveillance radars to obtain oceanic winds.

\section{Direction Finding}

In an early experiment Crombie et al. (1970) and Crombie (1972) used a multifrequency coherent radar with a pair of phased-receiving whip antennas to observe the growth of wave energy offshore of Barbados. Using one antenna in a nondirectional mode, Crombie also observed small but significant wave energy traveling in opposition to the wind (Crombie et al.. 1978). Direction-finding systems usually are used to measure currents rather than waves, as discussed in the next section.

\section{Wind Measurements}

Although HF radars do not directly respond to the wind, several researchers have estimated the direction and, in some cases, the speed of winds near the ocean surface by examining the signals scattered by the ocean waves raised in response to the wind. Long and Trizna (1973) used radar at Chesapeake Bay to map winds in the North Atlantic, and Stewart and Barnum (1975) evaluated the accuracy of that technique. Shearman and Wyatt (1982) describe the results of mapping winds during the JASIN experiment. Recent results from an experiment conducted at Duck. NC in 1994 show wind direction maps obtained with OSCR (Fernandez et al., 1997).

\section{Current Measurements}

Recently there has been considerable emphasis on mapping ocean currents. By examining the coherence between signals received on two closely spaced whips, Crombie (1972) observed that the phase of the coherence varied with Doppler frequency, implying that signals having different Doppler shifts were coming from different directions, and interpreted this as viewing a uniform current from different aspect angles. This result led to the development of the Coastal Ocean Dynamics Applications Radar (CODAR) (Barrick et al., 1977: Lipa and Barrick 1983), which is the subject of several papers in this issue (Barrick and Lipa, 1997: Bjorkstedt and Roughgarden. 1997: Paduan and Cook. 1997). The CODAR system extends Crombie's direction-finding array to a compact set of co-located antennas and thus requires very little beach space for operation. Phased-array radars have also been used to measure currents. Stewart and Joy (1974) used a multifrequency radar on San Clemente Island to measure the ver- tical current shear at two bearings. Ha (1979) used the multifrequency Stanford radar with a highly directional transmitting antenna to measure currents along its boresight and compared his measurements with drifting spar buoys. The same radar was used with a phased-array receiving antenna at Granite Canyon, south of Monterey, to study the effects of upwelling along the California coast (Fernandez. 1993; Shkedy et al., 1995: Fernandez et al., 1996). Maresca et al. (1980) examined tidal currents in the San Francisco Bay. Building on work by the CODAR. NOAA Wave Propagation Laboratory, and Stanford groups, a new array type HF radar system for the commercial market was developed by Marex Ltd., England. This radar, called Ocean Surface Current Radar (OSCR), uses a 16-element antenna array $\sim 80 \mathrm{~m}$ long. OSCR instruments have been used for mapping tidal and residual surface currents along the coasts of Britain (Prandle, 1987). OSCR units have been sold in the United States: the Rosenstiel School of Marine and Atmospheric Science of the University of Miami used a pair of OSCR radars for coastal observations in a number of locations (Shay et al., 1995; Graber et al., 1996). A new multifrequency radar was constructed jointly by the University of Michigan, the Environmental Institute of Michigan. and Stanford and is in operation at Santa Cruz, CA.

\section{Conclusions}

Over the past 25 years HF radar systems have been used to measure the directional distribution of wave energy in the open ocean. the growth of waves offshore after a sudden change in wind direction because of a frontal passage, ocean current shear from a ship in the open ocean, and current and current shear from land-based locations. With proper calibration and data processing. HF radar is capable of providing wide-area measurements that are difficult or impossible to make any other way. and the radar data can provide useful supplements to conventional oceanographic measurements.

\section{References}

Barrick, D.E., 1978: HF radio oceanography-a review. Boundary-Laver Meteorol., 13, 23 44.

- M.W. Evans and B.L. Weber. 1977: Ocean currents mapped by radar. Science, 198, 138-144.

- and B.J. Lipa. 1997: Evolution of bearing determination in HF current-mapping radars. Oceanography, 10 , 72-75.

Bjorkstedt. E. and J. Roughgarden. 1997: Larval transport and coastal upwelling: an application of HF radar in ecological research. Oceanography, 10, 64-67.

Broche. P.. 1979: Estimation du spectre directionnel des vagues par radar decametrique coherent. In: $A G A R D$ Conference Proceedings on Special Topics in $H F$ Propagation, 263. AGARD, Clearinghouse for Federal Scientific and Technical Information. Springfield. VA, 31-1-31-12.

Croft. T.A.. 1972: A means for observing our environment at great distances. Rev. Geophys. Space Phys., 10, 73155.
HF radar is capable

of providing wide-

area measurements

that are difficult or

impossible to make

any other way . . . 
Crombie. D.D., 1955: Doppler spectrum of sea echo at 13.56 Mc/s. Nature, 175, 681-682.

, 1972: Resonant backscatter from the sea and its application to physical oceanography. IEEE International Conference Proceedings on Engineering in the Ocean Environment. IEEE, New York, 174-179.

—, K. Hasselmann and W. Sell, 1978: High-frequency radar observations of sea waves travelling in opposition to the wind. Boundary-Laver Meteorol., 13, 45-54.

_ J.M. Watts and W.M. Beery, 1970: Spectral characteristics of HF ground wave signals backscattered from the sea. AGARD Conference Proceedings, 77, AGARD, Clearinghouse for Federal Scientific and Technical Information, Springfield. VA, 16-1-16-6.

Fernandez, D.M., 1993: High-frequency radar measurements of coastal ocean surface currents. Ph.D. dissertation, Stanford University, $191 \mathrm{pp}$.

, J.F. Vesecky and C.C. Teague, 1996: Measurements of upper ocean surface current shear with high-frequency radar. J. Geophys. Res., 101, 28,615-28.625.

- H.C. Graber, J.D. Paduan and D.E. Barrick, 1997: Mapping wind direction from HF radar. Oceanography, $10,93-95$.

Georges, T.M. and J.A. Harlan, 1994: New horizons for overthe-horizon radar? IEEE Antennas Propag. Magazine, $36,14-24$.

Graber, H.C., D.R. Thompson and R.E. Carande, 1996: Ocean surface features and currents measured with SAR interferometry and HF radar. J. Geophys. Res., 101. 25813-25832.

Ha, E.C. 1979: Remote sensing of ocean surface current and current shear by HF backscatter radar. Ph.D. dissertation Tech. Rep. D415-1, Stanford Electronics Labs, Stanford University, $134 \mathrm{pp}$.

Lipa, B.J. and D.E. Barrick, 1983: Least-squares method for the extraction of surface currents from CODAR crossedloop data: application at ARSLOE. IEEE J. Ocean Eng., $8,226-253$

Long, A.E. and Trizna, D.B., 1973: Mapping of North Atlantic winds by $\mathrm{HF}$ radar sea backscatter interpretation, IEEE Trans. Antennas Propag.. AP-21, 680-685.

Maresca, J.W., Jr. and T.M. Georges. 1980: Measuring rms waveheight and the scalar ocean wave spectrum with HF sky wave radar. J. Geophys. Res., 85, 2759-2771.

—, Jr., R.R. Pladden, R.T. Cheng and E. Seibel, 1980: HF radar measurements of tidal currents flowing through the San Pablo Strait, San Francisco Bay. Limnol. Oceanogr., 25, 929-935.

Paduan, J.D. and M.S. Cook, 1997: Mapping currents in Monterey Bay with CODAR-type HF radar. Oceanography, $10,49-52$.

Peterson, A.M., C.C. Teague and G.L. Tyler, 1970: Bistatic radar observations of long-period directional oceanwave spectra with LORAN-A. Science, 170, 158-161.

Prandle, D., 1987: The fine-structure of nearshore tidal and residual circulations revealed by H.F. radar surface current measurements. J. Phys. Oceanogr., 17, 231-245.

Shay, L.K.. H.C. Graber, D.B. Ross and R.D. Chapman, 1995: Mesoscale ocean surface current structure detected by high-frequency radar. J. Atmos. Ocean. Tech., 12, 881-900.

Shearman, E.D.R., 1981: Remote sensing of ocean waves, currents and surface winds by dekameter radar. In: Remote Sensing in Meteorology, Oceanography and Hydrology. A.P. Cracknell, ed., Ellis Horwood, London, 312-334.

1983: Radio science and oceanography. Radio Sci.. 18, 299-320.

and L.R. Wyatt, 1982: Dekametric radar for surveillance of sea-state and oceanic winds. J. Navig., 35, 397-409.

, W.A. Sandham, E.N. Bramley and P.A. Bradley, 1979: Ground-wave and sky-wave sea-state sensing experiments in the UK. AGARD Conference Proceedings on Special Topics in HF Propagation, 263, AGARD, Clearinghouse for Federal Scientific and Technical Information, Springfield. VA, 30-1-30-11.

Shkedy, Y., D. Fernandez, C. Teague. J. Vesecky and J. Roughgarden, 1995: Detecting upwelling along the central coast of California during an El Niño year using HF-radar. Cont. Shelf Res., 15, 803-814.

Stewart, R.H. and J.W. Joy, 1974: HF radio measurement of surface currents. Deep-Sea Res., 21, 1039-1049.

, J.R. Barnum, 1975: Radio measurements of oceanic winds at long ranges: an evaluation. Radio Sci., 10, 853-857.

and C.C. Teague, 1980: Dekameter radar observations of ocean wave growth and decay. J. Phys. Oceanography, 10, 128-143.

Teague, C.C., 1971: Bistatic radar techniques for observing long wavelength directional ocean-wave spectra. IEEE Trans. Geosci. Electr., GE-9, 211-215.

- 1986: Multifrequency HF radar observations of currents and current shears. IEEE J. Ocean. Eng., OE-11, 258-269.

, G.L. Tyler and R.H. Stewart, 1975: The radar cross section of the sea at $1.95 \mathrm{MHz}$ : comparison of in-situ and radar determinations. Radio Sci.. 10, 847-852.

Tyler, G.L.. C.C. Teague, R.H. Stewart, A.M. Peterson, W.H. Munk and J.W. Joy, 1974: Wave directional spectra from synthetic aperture observations of radio scatter. Deep-Sea Res., 21, 989-1016.

Vesecky, J.F., S.V. Hsiao, C.C. Teague, O.H. Shemdin and S.S. Pawka, 1980: Radar observations of waves in the vicinity of islands. J. Geophys. Res., 85 , 4977-4986. 